\title{
Convention, Form, and Figurative Language Processing
}

\author{
Dedre Gentner \\ Department of Psychology \\ Northwestern University \\ Brian F. Bowdle \\ Department of Psychology \\ Indiana University
}

There are 2 basic controversies concerning how metaphors are processed. First, are metaphoric mappings more akin to literal comparisons or to literal categorizations? And second, is metaphor comprehension indirect or direct? We believe that these controversies are more apparent than real and that a unified theoretical framework can be offered that reconciles these opposing views. The central idea is that all metaphors involve structural alignment of the target and base domains. Whether these alignments are more akin to comparisons or to categorizations, and whether they are computed directly or indirectly, depends on 2 factors: the type of representation invoked by the base term and the linguistic form of the metaphor.

Metaphors establish mappings between concepts from disparate domains of knowledge. For example, in the metaphor "The mind is a computer," an abstract entity is described in terms of a complex electronic device. It is widely believed that metaphors are a major source of conceptual change. In the field of cognitive psychology, the computer metaphor resulted in a new way of conceptualizing the mind and has inspired researchers to postulate a vast array of mental constructs. Indeed, it has recently been claimed that metaphors may be the primary (if not the only) mechanism for reasoning with abstract concepts-metaphors allow us to structure vague or ambiguous ideas in terms of more concrete realms of experience (e.g., Gibbs, 1994; Lakoff \& Johnson, 1980; Lakoff \& Turner, 1989). Given such claims,

Requests for reprints should be sent to Brian F. Bowdle, Department of Psychology, Indiana University, Bloomington, IN 47405. E-mail: bbowdle@indiana.edu 
the question of how metaphors are processed has taken a central place in the cognitive sciences. No simple answers to this question have emerged, however, and the metaphor literature is fraught with contradictory claims and evidence.

Traditional theories of language processing view metaphors as deviations from the linguistic norms governing literal language-deviations that must be corrected or sidestepped for comprehension to occur. One version of the deviance position treats metaphors as anomalous expressions that violate semantic or syntactic rules (e.g., Chomsky, 1961; Katz, 1964; Kintsch, 1974). A second and more influential version of this position treats metaphors as literally false expressions that violate conversational maxims of communication (e.g., Grice, 1975, 1978; Searle, 1979). In either view, metaphors cannot be interpreted directly. Rather, the hearer must invoke a three-stage comprehension process:

1. Derive a literal interpretation of the statement.

2. Assess the soundness of the literal interpretation given the context of the statement.

3. Derive a metaphoric interpretation if the literal one is found to be anomalous or false.

Such indirect processing models of metaphor have largely fallen out of favor, and a number of studies have failed to support two key predictions of the deviance position. First, if literal interpretations always precede metaphoric interpretations, then metaphors should require additional processing time over literal statements. Given sufficient context, however, metaphors often take no longer to read than literals (e.g., Inhoff, Lima, \& Carroll, 1984; Ortony, Schallert, Reynolds, \& Antos, 1978; Shinjo \& Myers, 1987). Second, if literal interpretations are obligatory, then metaphoric interpretations should only be sought when literal ones are defective. However, metaphoric meanings are often generated automatically and in parallel with literal meanings (e.g., Gildea \& Glucksberg, 1983; Glucksberg, Gildea, \& Bookin, 1982; Keysar, 1989). On the basis of these results, most researchers now believe that metaphors are interpreted directly and that the processes involved in comprehending literal and metaphoric language are essentially the same.

At the same time, it must be recognized that the available evidence does not unanimously support these conclusions. For one thing, the apparent ease with which metaphors were interpreted in many of the previously mentioned studies relied heavily on the presence of prior contexts that primed their figurative meanings. In the absence of such contexts, metaphors took longer to read than literal statements (Inhoff et al., 1984; Ortony et al., 1978; Shinjo \& Myers, 1987), and their figurative meanings were not generated automatically (Gildea \& Glucksberg, 1983). Furthermore, some studies have found that metaphors consistently take longer to comprehend than literal statements, regardless of the presence of a supporting context (e.g., Gerrig \& Healy, 1983; Janus \& Bever, 1985). 
Even if it is accepted that literal and metaphoric language are both interpreted directly and involve the same comprehension processes, the question remains as to what exactly these processes are. That is, how do metaphors establish mappings between different domains of knowledge? The standard view is that metaphors such as "Time is a river" are understood as comparison statements, in which the hearer seeks to find common properties of the target (a-term) and the base (b-term; e.g., Miller, 1979; Ortony, 1979; Tversky, 1977). The notion that metaphors establish similarity relations between ontologically distinct concepts is highly intuitive, and there is some empirical support for this position. For example, the degree of similarity between target and base has been found to be positively related to the aptness and interpretability of metaphors (Johnson \& Malgady, 1979; Malgady \& Johnson, 1976; Marschark, Katz, \& Paivio, 1983), as well as to the speed of metaphor comprehension (Gentner \& Wolff, 1997). However, a growing number of researchers have proposed that metaphors are best treated as categorization statements rather than as comparison statements (e.g., Glucksberg \& Keysar, 1990; Glucksberg, McGlone, \& Manfredi, 1997; Honeck, Kibler, \& Firment, 1987; Kennedy, 1990-but see Chiappe \& Kennedy, 2001/this issue). That is, metaphors establish class-inclusion relations between ontologically distant concepts. In this view, the base concept of a metaphor such as "Time is a river" is used to derive an ad hoc metaphoric category of which it represents a prototypical member (e.g., "things that flow forward"). Once this metaphoric category has been abstracted, the target concept is understood as being a member of the category.

To summarize, there are two basic controversies concerning how metaphors are processed. First, are metaphoric mappings more akin to literal comparisons or to literal categorizations? And second, is metaphor comprehension indirect or direct? We believe that these controversies are more apparent than real and that a unified theoretical framework can be offered that reconciles these opposing views. The central idea is that all metaphors involve structural alignment of the target and base domains-metaphors act to set up correspondences between isomorphic conceptual structures. Whether these alignments are more akin to comparisons or to categorizations, and whether they are computed directly or indirectly, depends on two factors: the type of representation invoked by the base term and the linguistic form of the metaphor. Before considering the effects of these two factors on metaphor comprehension, however, it is necessary to examine the notion of structural alignment in greater depth.

\section{STRUCTURAL ALIGNMENT IN METAPHOR}

The primary contrast between comparison and categorization models of metaphor comprehension concerns the taxonomic relation between the target and base. In comparison models, the target and base representations are understood at roughly 
the same level of abstraction. In categorization models, the target representation is subordinate to the base representation. Orthogonal to the issue of taxonomic relation, however, is the issue of what kinds of properties are mapped from the base to the target. There is considerable evidence that metaphors establish links between conceptual systems in the target and base domains, in which relational correspondences are emphasized over correspondences between isolated object attributes (e.g., Carbonell, 1981; Gentner, 1983; Gentner, Falkenhainer, \& Skorstad, 1988; Indurkhya, 1987; Kittay \& Lehrer, 1981; Lakoff, 1986; Lakoff \& Johnson, 1980; Tourangeau \& Stemberg, 1981, 1982; Turner, 1987; Verbrugge \& McCarrell, 1977). In other words, metaphor can be seen as a species of analogy.

Gentner's $(1983,1989)$ structure-mapping theory is among the most clearly articulated and extensively studied of these analogical approaches to metaphor comprehension. Structure-mapping theory assumes that interpreting a metaphor involves two stages: alignment and projection. The alignment process operates to create a maximal structurally consistent match between two representations that observes one-to-one mapping and parallel connectivity (Falkenhainer, Forbus, \& Gentner 1989). That is, each element of one representation can be placed in correspondencr with, at most, one element of the other representation, and arguments of aligned rela tions are themselves aligned. A final constraint on the alignment process i: systematicity: Alignments that form deeply interconnected structures, in whic] higher order relations constrain lower order relations, are preferred over less system atic sets of commonalities. Once a structurally consistent match between the targe and base domains has been found, further predicates from the base that are cor nected to the common system can be projected to the target as candidate inference: These mechanisms are embodied by the structure-mapping engine (SME), a compl tational model that simulates analogical comparison (Falkenhainer et al., 198! Forbus, Gentner, \& Law, 1995).

To better illustrate these processes, consider the metaphor "Men al wolves. "Given the simple target and base representations shown in Figure structure-mapping theory predicts the following sequence of events in inte preting the metaphor. First, the shared relation prey on is aligned. Next, $t]$ nonidentical arguments of this identical relation are aligned by parallel conne tivity: wolves $\rightarrow$ men and animals $\rightarrow$ women. Finally, predicates that a unique to the base but connected to the aligned structure (i.e., those predicat specifying that the predatory behavior is instinctive) are carried over to the $t$ : get. Thus, the metaphor would be interpreted as meaning something like, " $M$ instinctively prey on women."

Note that the candidate inference mechanism strongly differentiates str ture-mapping theory from traditional comparison models (e.g., Miller, 19 Ortony, 1979; Tversky, 1977), which cannot convey new information (beyc merely highlighting common properties; see Gentner \& Wolff, 1997; Glucksb \& Keysar, 1990; Glucksberg et al., 1997). In structure mapping, the projectior 


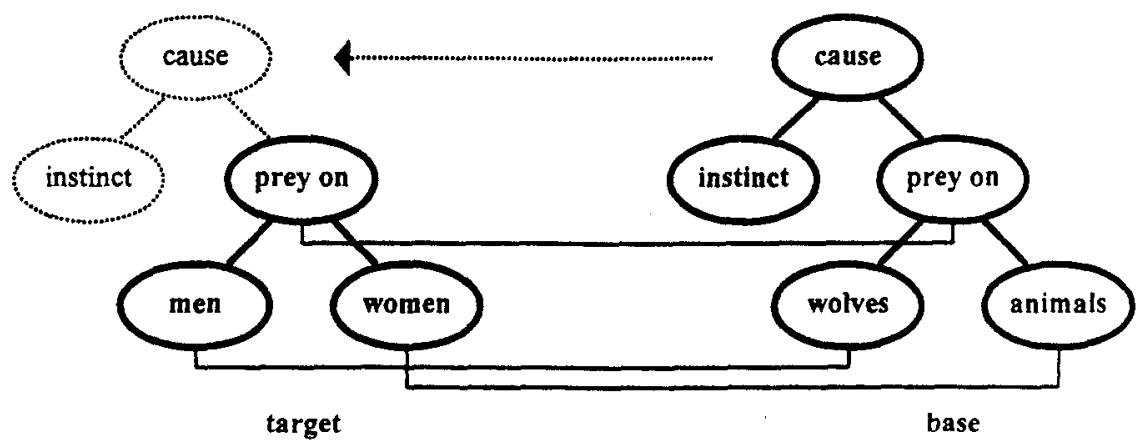

FIGURE 1 A structure-mapping interpretation of the metaphor "Men are wolves. "From $A d$ vances in Analogy Research (p. 301), by Bowdle, 1998a, Sofia, Bulgaria: New Bulgarian University. Copyright 1998 by New Bulgarian University. Adapted with permission.

candidate inferences is perfectly compatible with alignment. Indeed, a prior alignment is necessary to ensure appropriate inference projection.

In many metaphors (as in analogies), the focus is on relational commonalities, and corresponding objects in the target and base need not be similar (Gentner \& Clement, 1988; Shen, 1992). Thus, in the previous example, the alignment of the target men and the base wolves was determined primarily by the matching relation prey on. However, the way in which men prey on women is different from the way in which wolves prey on animals: Men chase after women for sexual gain, whereas wolves hunt other animals for food. This situation, in which matching predicates contain domain-specific differences, is typical of metaphors (e.g., Ortony, 1979; Tourangeau \& Sternberg, 1981). Metaphoric mappings may therefore typically require rerepresentation in one or both terms. In particular, domain-specific features of matching predicates may be omitted so that the common structure is made more obvious (see Clement, Mawby, \& Giles, 1994, for a review of this and other modes of rerepresentation). Note that this type of rerepresentation is far less typical of literal mappings, be they comparisons (e.g., "An orange is like a lemon") or categorizations (e.g., "Pepper is a spice"). This is because the target and base of a literal mapping will tend to occupy the same ontological domain, and matching predicates will therefore contain few if any domain-specific differences.

\section{METAPHOR AND POLYSEMY}

Like analogies, metaphors lend additional structure to problematic target concepts, thereby making these concepts more coherent (e.g., Bowdle \& Gentner, 1997; Clem- 
ent \& Gentner, 1991). According to structure-mapping theory, this is accomplished by means of inference projection. However, this is not the only way in which metaphors can lead to conceptual change. Metaphors are also a primary source of polysemy-they allow words with specific meanings to take on additional, related meanings (e.g., Glucksberg \& Keysar, 1990; Lakoff, 1987; Lehrer, 1990; Miller, 1979; Nunberg, 1979; Sweetser, 1990). For example, consider the word roadblock. There was presumably a time when this word referred only to a barricade set up in the road. With repeated metaphoric use, however, roadblock has acquired the secondary sense "anything that blocks progress" (as in "Fear is a roadblock to success").

We believe that the relation between metaphor and polysemy is key to resolving the opposition between comparison and categorization models of metaphor comprehension. We begin by considering how metaphors create new word meanings. Our claim is that structural alignment during metaphor comprehension allows for the induction of abstract relational schemas, which may in turn be lexicalized as secondary senses of metaphor base terms (Bowdle, 1998a, 1998b; Bowdle \& Gentner, 1995; Gentner \& Wolff, 1997). We refer to this evolution as the career of metaphor.

When a metaphor is first encountered, both the target and base terms refer to specific concepts from different ontological domains, and the metaphor is interpreted by (a) aligning the two representations; and (b) importing predicates from the base to the target, which then count as further matches. As a result of this mapping, the common relational structure that forms the basis of the metaphor interpretation will increase in salience relative to domain-specific differences between the two representations. That is, alignable predicates will become more strongly activated, whereas nonalignable predicates will be suppressed (Gernsbacher, Keysar, \& Robertson, 1995; Glucksberg, Newsome, \& Goldvarg, 2001/this issue). The highlighted system may in turn give rise to an abstract metaphoric category of which the target and base can be seen as instances. This is akin to the induction of domain-general problem schemas during the course of analogical problem solving (e.g., Bassok \& Holyoak, 1989; Brown, Kane, \& Echols, 1986; Gick \& Holyoak, 1983; Loewenstein, Thompson, \& Gentner, 1999; Novick \& Holyoak, 1991; Ross \& Kennedy, 1990).

In this view, metaphoric categories are created as a byproduct of the comparison process and may be stored separately from the original target and base concepts. If a hearer never again encounters a metaphor that generates the same metaphoric category, then the abstraction may eventually decay. However, if a given metaphor base is repeatedly aligned with different targets so as to yield the same basic interpretation, then the abstraction will not only gain in stability, but may also become conventionally associated with the base term. At this point, the base term will be polysemous, having both a domain-specific meaning and a related domain-general meaning.

Of course, not just any metaphor can lead to lexical extension of the base term. There are two important constraints on the metaphoric creation of polysemous words. First, the alignment of the target and base concepts must be able to suggest a 
coherent category. Mappings that focus on relational structures are therefore more likely to generate stable abstractions than mappings that focus on less systematic object descriptions (see also Ramscar \& Pain, 1996; Shen, 1992). For example, the metaphor "The sun is a tangerine" elicits two common attributes of the target and base: Both are round, and both are orange in color. However, these two attributes are not systematically related. The metaphor is therefore unlikely to suggest a category of things that are round and orange in color, and it will not lead to lexical extension of the base term tangerine. Second, if a metaphor is able to suggest a coherent category, the abstraction must not already be lexicalized. This follows from Clark's (1992) principle of pre-emption by synonymy: If a potential innovative use of a term is synonymous with a well-established term, then the innovative term will be pre-empted by the well-established one and will therefore be considered unacceptable. For example, the metaphor "An encyclopedia is a silver mine" elicits the common property of being a source of something valuable. However, this meaning is already lexicalized by the metaphoric base term gold mine. The term silver mine is therefore unlikely to acquire this meaning as a secondary sense.

\section{METAPHOR CONVENTIONALITY}

One implication of the career of metaphor hypothesis is that different classes of metaphors can be defined in terms of (a) whether the base term evokes a metaphoric category, and (b) how this abstraction is related to the literal base concept. Figure 2 shows four possible classes of metaphors that are consistent with the present theoretical framework. Novel metaphors involve base terms that refer to a domain-specific concept, but are not (yet) associated with a domain-general category. For example, the novel base term glacier (as in "Science is a glacier") has a literal sense-_"a large body of ice spreading outward over a land surface"-but no related metaphoric sense (e.g., "anything that progresses slowly but steadily"). In contrast, conventional metaphors involve base terms that refer both to a literal concept and to an associated metaphoric category. For example, the conventional base term blueprint (as in "A gene is a blueprint") has two closely related senses: "a blue and white photographic print in showing an architect's plan" and "anything that provides a plan." Conventional base terms are polysemous, and the literal and metaphoric meanings are semantically linked due to their obvious similarity.

Note that metaphor conventionality is not the same as metaphor familiarity. Conventionalization involves repeated figurative uses of a given base term, so that it acquires a domain-general meaning. Familiarization, however, involves repeated exposures to specific target-base pairings, as has occurred with the well-known metaphor "Time is money. "In essence, familiarization leads to the creation of stock expressions as opposed to stock base terms. 


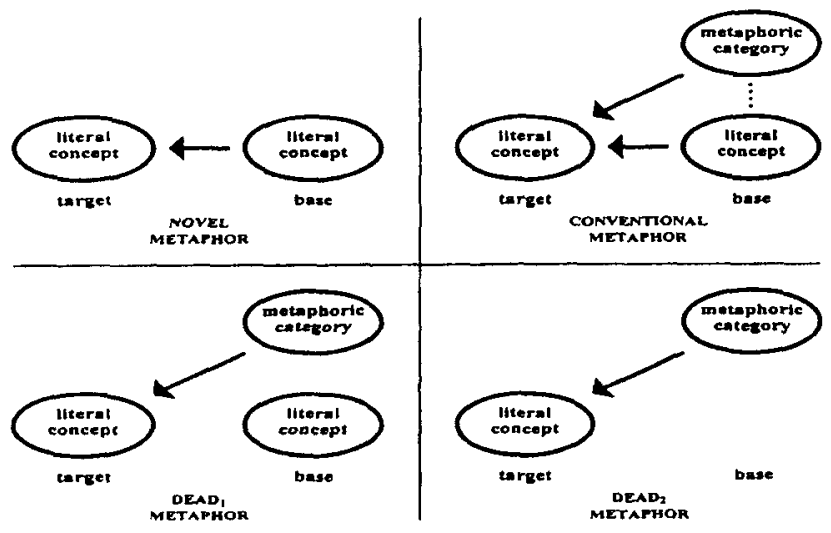

FIGUAE 2 Four types of metaphors. From Advances in Analogy Research (p. 303), by Bowdle, 1998a, Sofia, Bulgaria: New Bulgarian University. Copyright 1998 by New Bulgarian University. Adapted with permission.

The ultimate conclusion of the career of metaphor occurs when the relation between the derived metaphoric category and the original base concept is no longer recognized. At this stage, any expression using the metaphoric sense of the base term is a dead metaphor and will not seem metaphoric. Figure 2 shows two possible types of dead metaphors. Dead/ metaphors are similar to conventional metaphors, except that the two representations evoked by the base term are no longer semantically linked. That is, dead, base terms are homonymous rather than polysemous. For example, consider the statement "A university is a culture of knowledge. "Here, the word culture refers to a particular heritage or society, and its use seems quite literal. In fact, this sense of culture is a metaphoric extension of another commonly known sense of the word: "a preparation for growth" (as in the culture of the vine or bacteria culture). However, these two meanings no longer seem related. This is perhaps because the once-abstract metaphoric category has, through repeated application to the domain of human affairs, acquired new domain-specific features. In contrast, dead ${ }_{2}$ metaphors involve base terms that refer only to a derived metaphoric category-the original base concept no longer exists. An example of this is the dead, base term blockbuster (as in "The movie 'Titanic' was a blockbuster'), which means "anything that is highly effective or successful." However, most people are unaware that this word originally referred to a very large bomb that could demolish an entire city block. Thus, expressions containing the word blockbuster will be interpreted solely in terms of this word's derived meaning.

\section{Processing Implications}

The career of metaphor hypothesis has clear implications for the effects of conventionality on metaphor processing. Consider again the classes of metaphors shown in Figure 
2. In novel metaphors, both the target and base terms refer to domain-specific concepts at roughly the same level of abstraction. Novel figurative statements will therefore be interpreted as comparisons, in which the target concept is structurally aligned with the literal base concept. In conventional metaphors, however, the base term is polysemous-it refers both to a domain-specific concept and to a related domain-general category. Conventional figurative statements may therefore be interpreted either as comparisons, by aligning the target concept with the literal base concept, or as categorizations, by aligning the target concept with the metaphoric category named by the base term. Finally, in dead metaphors, only the metaphoric category named by the base will be applied to the target- the original base concept either seems irrelevant (dead meta- $^{-}$ phors) or is no longer available ( dead $_{2}$ metaphors).

Thus, as metaphors become increasingly conventional, there is a shift in mode of processing from comparison to categorization (Bowdle, 1998a, 1998b; Bowdle \& Gentner, 1995; Gentner \& Wolff, 1997). This account is similar to a number of recent proposals, according to which the interpretation of novel metaphors involves sense creation, but the interpretation of conventional metaphors involves sense retrieval (e.g., Blank, 1988; Blasko \& Connine, 1993; Giora, 1997; Martin, 1992; Tumer \& Katz, 1997). In this view, sense retrieval during conventional metaphor comprehension involves accessing prestored metaphoric categories. However, whereas these alternative proposals suggest that only conventional figurative statements are processed as directly as literal language, we believe that novel figurative statements may also be processed directly under certain circumstances. Furthermore, because conventional base terms refer to both a literal concept and an associated metaphoric category, the comprehension of conventional figuratives need not always involve sense retrieval. To determine exactly how a metaphor is processed, one must pay attention not only to the conventionality of the statement, but also its linguistic form.

\section{THE METAPHOR/SIMILE DISTINCTION}

Nominal metaphors (figurative statements of the form " $X$ is $Y^{\text {") }}$ can often be paraphrased as similes (figurative statements of the form " $X$ is like $Y$ "). For example, one can say both "The mind is a computer" and "The mind is like a computer. "This linguistic alternation is interesting because metaphors are grammatically identical to literal categorization statements (e.g., "A sparrow is a bird"), and similes are grammatically identical to literal comparison statements (e.g., "A sparrow is like a robin"). Assuming that form typically follows function in both literal and figurative language, metaphors and similes may tend to promote different comprehension strategies. Specifically, metaphors should invite classifying the target as a member of a category named by the base, whereas similes should invite comparing the target to the base. We refer to this link between form and function in figurative language as grammatical concordance. 
The notion of grammatical concordance is supported by a number of studies that have found clear differences between metaphors and similes in terms of their interpretation and evaluation (e.g., Aisenman, 1999; Chiappe \& Kennedy, 1999; Gibb \& Wales, 1990; Glicksohn, 1994; Gregory \& Mergler, 1990; Kennedy, 1982; Verbrugge, 1980). Gibb and Wales found that abstract base terms (e.g., beauty, imprisonment) were more likely than concrete base terms (e.g., cloud, pearl) to be associated with a preference for metaphors over similes. This makes sense if metaphors, unlike similes, invite categorizations and therefore apply most naturally when the base term is at a higher level of abstraction than the target term. Gregory and Mergler found that similes were more likely than metaphors to elicit potential similarities between unrelated targets and bases. This supports the claim that similes, unlike metaphors, invite comparisons and therefore are more likely to involve a search for common properties.

\section{Processing Implications}

According to the career of metaphor hypothesis, there is a shift in mode of processing from comparison to categorization as figurative statements become increasingly conventional. According to the notion of grammatical concordance, metaphors invite categorizations, whereas similes invite comparisons. Given these two claims, we are now in a position to describe exactly how different types of figurative statements are comprehended. Consider first the case of novel figuratives. Because novel base terms refer only to a domain-specific concept, novel figuratives can only be interpreted as comparisons. Therefore, when such statements are phrased as metaphors, comprehension will initially be thwarted: The metaphor form invites categorization, but there is no abstract metaphoric category associated with the base. The hearer must then reinterpret the metaphor as a comparison between the target and base concepts. However, when such statements are phrased as similes, comprehension is direct: The simile form invites comparison, which accords with the mode of processing required by novel figuratives.

Now consider the case of conventional figurative statements. Because conventional base terms refer both to a domain-specific concept and a domain-general category, conventional figuratives may be interpreted as either comparisons or categorizations. Therefore, when such statements are phrased as metaphors, comprehension is direct: The metaphor form invites categorization, and the base term provides a metaphoric category to align with the target. Likewise, when such statements are phrased as similes, comprehension is again direct: The simile form invites comparison, and the base term provides a literal concept to align with the target.

Thus, there is a processing interaction between conventionality and grammatical form for figurative statements, as summarized in Table 1. Novel metaphors and similes are both interpreted as comparisons. However, novel metaphors are inter- 
TABLE 1

Processing Effects of Conventionality and Grammatical Form

\begin{tabular}{|c|c|c|c|}
\hline Conventionality & Form & Process & Application \\
\hline novel & metaphor & comparison & indirect \\
\hline novel & simile & comparison & direct \\
\hline conventional & metaphor & categorization & direct \\
\hline conventional & simile & comparison & direct \\
\hline
\end{tabular}

preted indirectly, whereas novel similes are interpreted directly. In contrast, conventional metaphors are interpreted as categorizations, but conventional similes are interpreted as comparisons. Furthermore, conventional metaphors and similes are both interpreted directly.

Two caveats must be made here. First, in claiming that novel metaphors are processed indirectly, we mean simply that such expressions will garden-path the hearer: The metaphor form promotes a search for a superordinate base representation that does not exist. This is quite different from more traditional notions of indirect processing in metaphor comprehension, where the hearer attempts to find figurative similarities between the target and base concepts only after having failed to locate any literal similarities. Indeed, the process of alignment, as modeled in SME, typically creates two or three simultaneous interpretations (which are the largest and deepest systems of interconnected predicates plus their candidate inferences). These may be either literal or figurative; the processing mechanism is indifferent to this distinction. On this account, the same mechanism is involved in literal inference projection-for example, inferring from "This Chevy is (ike) a Cadillac" that the Chevy has a luxurious ride-as in metaphoric inference projection--for example, inferring from "This job is (like) a jail" that the job is particularly onerous.

Second, in claiming that conventional figurative statements may be processed as either categorizations or comparisons depending on their grammatical form, we do not wish to imply that the metaphor/simile distinction is the only factor involved in determining which mode of alignment will be used by the hearer. Other factors may also influence which of the two representations of the base term--the literal concept or the metaphoric category-will be favored during comprehension, including the context of the metaphor and the relative salience of each meaning of the base term (Giora, 1997; Katz \& Ferretti, 2001/this issue; Williams, 1992).

We have not yet considered the effects of grammatical form on the comprehension of dead figurative statements. Intriguingly, such statements often can only be phrased as metaphors-the simile form seems infelicitous. For example, most hearers would probably reject the statements "A university is like a culture of knowledge" and "The movie 'Titanic' was like a blockbuster" as misleading. After all, a university is a culture of knowledge, and the movie "Titanic" was a blockbuster. The fact that only the metaphor form seems appropriate is consistent with our claim that during the compre- 
hension of dead figurative statements, only the metaphoric category named by the base will be applied to the target-the original base concept either seems irrelevant or is no longer available. That is, such statements are interpreted strictly as categorizations. Because dead metaphors are only metaphoric in the historic sense, however, we will have little to say about them in the remainder of this article.

\section{EXPERIMENTAL EVIDENCE}

The career of metaphor hypothesis and the notion of grammatical concordance suggest a neat resolution to the two controversies reviewed earlier in this article: Are metaphoric mappings more akin to literal comparisons or to literal categorizations, and is metaphor comprehension indirect or direct? We have claimed that both sides in each of these debates are at least partially correct and that the manner in which a figurative statement is processed depends on both its conventionality and its linguistic form. To gain direct evidence for this unified theoretical framework, we conducted a series of experiments using a variety of converging methods and measures. These experiments have been reported in detail elsewhere (Bowdle, 1998b; Bowdle \& Gentner, 1995, 2001) and are summarized in the following.

\section{Grammatical Form Preferences}

If conventionalization results in a processing shift from comparison to categorization, then there should be a corresponding shift at the linguistic level from the comparison (simile) form to the categorization (metaphor) form. We gave individuals novel and conventional figurative statements in both grammatical forms and asked which form they preferred for each statement. Participants were also given statements in which the target was literally similar to the base (e.g., lemon $\rightarrow$ orange)-for which the comparison form is most natural -and statements in which the target was a member of a literal category named by the base (e.g., whale $\rightarrow$ mammal)-for which the categorization form is most natural.

As predicted, participants preferred similes more strongly for novel than for conventional figuratives. Indeed, the preference for the comparison form was as great for novel figuratives as for statements in which the target and base were literally similar. However, participants showed no strong preference for expressing conventional figuratives as similes or as metaphors. This is consistent with the claim that, because conventional base terms refer both to a literal concept and to a related metaphoric category, conventional figuratives may be interpreted as either comparisons or categorizations.

\section{Comprehension Times}

The career of metaphor hypothesis also makes clear predictions about the on-line comprehension of novel and conventional figurative statements. One prediction is 
that, if conventionalization results in a processing shift from comparison to categorization, then (averaging across grammatical forms) conventional figurative statements should be easier to interpret than novel figurative statements. Because metaphoric categories will be informationally sparser than the literal concepts they were derived from, mappings between a target and a metaphoric category will be computationally less costly than mappings between a target and a literal base concept. (In fact, previous studies focusing strictly on the metaphor form have confirmed that conventional expressions are comprehended more rapidly than novel expressions-see Blank, 1988; Blasko \& Connine, 1993).

A second and more interesting prediction concerns the effects of conventionality on the relative comprehension times of metaphors and similes. If novel figuratives are interpreted strictly as comparisons, then novel similes should be easier to comprehend than novel metaphors. This is because only the simile form directly invites comparison. At the same time, if conventional figuratives can be interpreted as either comparisons or categorizations, then-assuming that metaphoric categories will generally be informationally sparser than the literal base concepts they were derived from-conventional metaphors should be easier to comprehend than conventional similes. The metaphor form invites categorization and will therefore promote a relatively simple alignment between the target and the abstract metaphoric category named by the base. The simile form invites comparison and will therefore promote a more complex alignment between the target and the literal base concept.

We collected participants' comprehension times for novel and conventional figurative statements phrased as either metaphors or similes. The results were as predicted by the career of metaphor hypothesis. First, conventional figuratives were interpreted faster than novel figuratives. Second, there was an interaction between conventionality and grammatical form: Novel similes were faster than novel metaphors, but conventional metaphors were faster than conventional similes.

\section{Metaphoricity Ratings}

Metaphors, unlike either literal comparison statements or literal categorization statements, typically involve mappings between concepts from different semantic domains. Indeed, many theories of metaphor assume that semantic distance between the target and the base is a key factor in recognizing that a particular statement is metaphoric (e.g., Miller, 1979; Ortony, 1979; Tourangeau \& Sternberg, 1981,1982 ). In other words, metaphoricity arises from the tension generated by juxtaposing concepts from unrelated but potentially relatable domains, and the greater the semantic distance between the target and the base, the more metaphoric a statement will seem.

Given this view of metaphor recognition, the career of metaphor hypothesis makes two basic predictions. First, if conventionalization increases the likelihood 
of categorization processing, then (averaging across grammatical forms) novel figurative statements should seem more metaphoric than conventional figurative statements. Because literal base concepts will contain more domain-specific properties than derived metaphoric categories, they will generate more tension when aligned with target concepts from other semantic domains.

More critically, the tension view of metaphor recognition suggests a simple yet compelling test of the notion that novel metaphors and similes access the same base representations, whereas conventional metaphors and similes access different base representations. Specifically, if both novel metaphors and similes are processed as comparisons, in which the target concept is aligned with a literal base concept, then there is no reason to expect that novel metaphors and similes will differ in their metaphoricity. In contrast, if conventional metaphors are processed as categorizations but conventional similes may often be processed as comparisons, then conventional similes should in fact be more metaphoric than conventional metaphors. This is because the simile form invites a mapping between the target and a domain-specific base representation, whereas the metaphor form invites a mapping between the target and a domain-general base representation. Thus, conventional similes should be more likely than conventional metaphors to generate tension between the target and the base.

We gave participants novel and conventional figurative statements phrased as either metaphors or similes and asked them to rate the metaphoricity of each statement. The results were as predicted by the career of metaphor hypothesis. First, novel figuratives were rated as more metaphoric than conventional figuratives. Second, there was an interaction between conventionality and grammatical form: Novel metaphors and similes were equally metaphoric, but conventional similes were more metaphoric than conventional metaphors.

\section{Summary}

In the series of experiments reviewed previously, we found several pieces of evidence consistent with both the career of metaphor hypothesis and the notion of grammatical concordance. First, as figurative statements became increasingly conventional, there was a shift in participants' preference from the simile form to the metaphor form. Second, whereas novel figurative statements were easier to interpret as similes than as metaphors, the reverse was true for conventional figurative statements. And third, whereas novel similes and metaphors were rated as equally metaphoric, conventional similes were actually judged to be more metaphoric than conventional metaphors. Taken together, these findings support the following claims. Novel figurative statements are interpreted strictly as comparisons and are therefore most naturally expressed as similes. This is because the metaphor form invites a search for a superordinate base representation that does not exist for novel figuratives. In contrast, conventional figurative state- 
ments, which involve polysemous base terms, may be interpreted as either comparisons or categorizations and may therefore be naturally expressed as similes or as metaphors. More specifically, the simile form will promote aligning the target with the literal base concept, and the metaphor form will promote aligning the target with a metaphoric category named by the base term.

\section{THE METAPHOR/SIMILE DISTINCTION AGAIN}

In discussions of the distinction between metaphors and similes, many researchers have suggested that one form is more basic that the other. For example, Miller (1979) argued that the simile form is more basic and suggested that metaphors are in fact elliptical similes. Glucksberg and Keysar (1990) proposed the opposite view. Based on their claim that metaphors are inherently categorization statements, they argued that the metaphor form was basic and that similes are implicit metaphors. Thus, they suggested, similes must be transformed into metaphors to be understood and may convey less information than metaphors.

In our view, Glucksberg and Keysar (1990) were correct in insisting that the categorical form has psychological significance, but wrong to dismiss the simile form as a weaker variant. Indeed, in the last of the experiments reviewed previously, we found that people considered similes to be as or more metaphoric than metaphors. According to our grammatical concordance view, both the simile form and the metaphor form are linguistic signals that invite specific psychological processes. The metaphor form invites the search for a hierarchically appropriate category-that is, one whose representation can be applied without contradiction to the target concept. If such a representation is not found-as in the case of novel figuratives-the hearer is likely to experience a processing cost and perhaps a sense of puzzlement. The simile form invites comparison, which can be carried out on either a novel or a conventional figurative statement; thus, indiscriminate use of the simile form may be less disruptive than indiscriminate use of the metaphor form.

\section{TOWARD A UNIFIED ACCOUNT OF FIGURATIVE LANGUAGE PROCESSING}

Taken together, the career of metaphor hypothesis and the notion of grammatical concordance describe how conventionality and linguistic form interact during comprehension to determine whether a figurative statement is processed as a comparison or as a categorization, as well as whether this processing is direct or indirect. However, structure-mapping theory-which we used earlier to motivate the career of metaphor hypothesis-also suggests resolutions to some additional long-standing conundrums in the metaphor literature: 
1. Metaphor recognition: how and when metaphoric processing is initiated (instead of literal processing).

2. Metaphoric meaning: whether metaphors generate new information or merely reflect parallels.

3. Directionality: why metaphors are preferred in one direction over the other.

4. Global conceptual metaphors: how global metaphoric systems can arise.

We now consider each of these in turn.

Metaphor Recognition: How and When Is Metaphoric Processing Initiated?

On hearing the statement "Genghis Khan was a butcher," should one generate (a) the literal interpretation that Genghis Khan cut meat for a living before finding his true vocation or (b) the metaphoric interpretation that Genghis Khan was a crude and voracious killer? This issue is a problem for categorization models of metaphor comprehension, which must decide whether a metaphoric category is to be derived from the base. Of course, categorization models could resort to serial processing at this point, trying first the literal meaning and then the metaphoric category. However, empirical support for the view that metaphor is initiated only after literal processing fails is weak at best.

In structure-mapping theory, this problem does not arise. SME normally produces two or more interpretations of a comparison in parallel. In particular, it can derive literal and metaphoric interpretations simultaneously. For example, given "Genghis Khan was a butcher, "SME would compute both of the interpretations in parallel, consistent with the idea that we need not proceed serially from the literal to the figurative interpretation. We suspect that which interpretation is ultimately accepted will be based on the fit with the conversational context and background knowledge.

\section{Metaphoric Meaning: Do Metaphors Create New Knowledge or Merely Reflect Structural Parallels?}

Lakoff and his colleagues (Lakoff, 1987, 1990; Lakoff \& Johnson, 1980; Lakoff \& Turner, 1989) suggested that metaphors create meaning: Conceptual systems are projected from a familiar concrete or "embodied" domain to a more abstract domain, where they preserve the structure of the source domain (Lakoff's, 1990, invariance hypothesis). In contrast, Murphy (1996) proposed that metaphors do not provide new structure for the target domain, but rather reflect structural parallelism between two domains. Structure mapping incorporates aspects of both these accounts. According to structure-mapping theory, metaphor interpretation begins 
with structural alignment, but then projects further inferences from base to target that are consistent with, and connected to, the common alignment. Thus, it predicts both structural parallelism and a highly selective kind of meaning creation.

\section{Directional Asymmetry: How Can a Comparison Approach Account for the Strong Directionality of Metaphors?}

People show strong directional preferences for metaphors and similes. Thus, people tend to think that 1 is an intelligible metaphor, but that 2 is not:

\section{1. "Some jobs are jails."}

2. "Some jails are jobs."

Although such asymmetries have been taken as evidence against traditional comparison models of metaphor comprehension (e.g., Glucksberg \& Keysar, 1990; Glucksberg et al., 1997), they pose no special problem for the structure-mapping account of metaphor. We propose that asymmetry arises from the informative charge of metaphor: Once the initial alignment is established, in a well-formed metaphor, the base domain is expected to reveal new inferences or a new perspective on the target domain. Thus, people's directional preferences should reflect their desire for having a relatively systematic, well-structured domain as the base. Bowdle and Gentner (1997) verified that relative systematicity or coherence is a main determinant of the preferred directionality of a comparison. Participants read two brief passages, which were similar except that one passage contained a causal structure linking the events and the other did not. One group of participants was asked to choose which direction of comparison they preferred- $A$ is similar to $B$ or $B$ is similar to $A$. A second group of participants was asked which direction was more informative. A third group was simply given the two passages and asked to generate any inferences they chose from one passage to the other. The results were consistent across all these tasks: Participants preferred the more systematic passage as base, rated the comparison as more informative when the systematic passage was the base, and were overwhelmingly more likely to draw inferences from the more systematic passage to the less systematic one.

These findings establish a connection between inferential potential and preferred direction, as predicted by structure-mapping theory. Both speakers and hearers should prefer statements that place the more systematic representation in the base position. We suggest that systematicity imbalance explains the directional asymmetry of metaphor. For example, it fits with the observation that base domains are often experiential domains such as spatial relations; the relations in these domains are represented clearly and can provide inferential structure for other domains.

Although metaphor processing is clearly directional, however, it does not begin this way. Our evidence indicates that the initial stage in metaphor comprehension is a 
role-neutral alignment stage, which is followed by a directional stage of inference and adaptation. For example, Wolff and Gentner (2000) used a metaphor interference technique pioneered by Glucksberg et al. (1982) that taps into very early metaphor processing. In this task, participants are asked to judge statements as literally true or false. Glucksberg et al. found that participants could respond quickly and accurately to standard true and false statements, but found it hard to reject metaphors. Participants were slower to respond "false" to metaphors than to ordinary false statements. Thus, metaphoric meanings were processed even though they were irrelevant to the assigned task. Moreover, this metaphoric interference effect appeared very early in processing-at about $1,200 \mathrm{msec}$, well below the 2 to $4 \mathrm{sec}$ typical in metaphor comprehension tasks.

Wolff and Gentner (2000) reasoned that the metaphor interference technique could be used to probe whether early metaphoric processing is role-specific, by including reversed metaphors-for example, "Some handcuffs are contracts"-as well as forward metaphors-for example, "Some contracts are handcuffs. "If initial processing is role-specific, then only the forward direction should create interference. When the terms are reversed, the sentence should simply seem anomalous, because the base term will not provide a category that can fit with the target. (All the metaphors were pretested to ensure that they were strongly directional, so that only the forward direction made sense.) In contrast, if the initial process is structural alignment, then the early stages should be role-neutral: Both the forward and reversed directions should create interference. Only later in processing should participants notice the bizarreness of the reversed metaphors and show a preference for the forward metaphors.

The results replicated Glucksberg et al.'s (1982) interference effect: Metaphors took longer to reject than ordinary false statements, indicating early processing of metaphoric meaning. The key finding, however, was that reversed metaphors showed just as much interference as forward metaphors. That interference effects were independent of the order of the base and target terms is strong evidence for initial role-neutral processing, even for highly directional metaphors. A second study revealed that this symmetric early interference held true even for highly conventional "stock" metaphors-a class that seemed particularly likely to reveal role-specific processing. Finally, in a third study, Wolff and Gentner (2000) verified that the metaphors were directional when processed to completion, consistent with the claim that the initial alignment process is followed by directional adaptation and inference projection. These results are evidence for structure-mapping theory and against initial projection theories.

\section{How Can Psychological Models of Metaphor Account for Global Metaphoric Systems?}

Metaphors often occur in interrelated systems. For example, the computer metaphor of mind has given rise to a vast system of related correspondences, including "infor- 
mation processing," "encoding," "decoding," "indexing," "feedback," and "memory stores" (Boyd, 1979; Gentner \& Grudin, 1985). Lakoff and his colleagues have documented systems of mappings that pervade ordinary language (Lakoff, 1987; Lakoff \& Johnson, 1980) and have argued that many everyday expressions imply metaphoric parallels between abstract conceptual structures and knowledge structures grounded in our experience with the physical world. Thus, a challenge to psychological theories of metaphor is whether process models that explain how individual metaphors are interpreted can also deal with such global systems.

Structure-mapping theory explains global metaphoric systems in terms of generative mappings between structured conceptual domains (Gentner, Bowdle, Wolff, \& Boronat, 2001). Gentner and Boronat $(1992,1999)$ conducted an empirical test of the domain-mapping hypothesis (Boronat, 1990; Gentner \& Wolff, 2000 ). If metaphors are processed by structural alignment, then extended metaphoric mappings should be processed fluently as long as they preserve the domain mapping. Thus, people should be faster to read sentences that consistently extend the existing structural alignment than to read sentences based on a different mapping. For example, after reading Sentence 1, people should read Sentence 2a faster than Sentence $2 b$.

1. "Her anger had been simmering all afternoon."

2a. "When Harry got home, she was boiling over."

2b. "When Harry got home, she was glacially cool."

Gentner and Boronat found evidence that people process extended metaphors as systematic structure-mappings (Boronat, 1990; Gentner, 1992; Gentner \& Boronat, 1992; Gentner et al., 2001; see also Gentmer \& Imai, 1992; Gentner, Imai, $\&$ Boroditsky, 2000).

To avoid asking for direct intuitions on metaphoric language, Gentner and Boronat (1992) developed an indirect technique based on the 'mixed metaphor' boggle so often captured in examples from The New Yorker, such as "The ship of state is sailing towards a volcano." Participants read passages containing extended metaphors such as " $A$ debate is $a$ war" and their sentence-by-sentence reading time was recorded. The last sentence of each passage was always a metaphor, drawn from either the same base domain (consistent) or a different base domain (inconsistent) as that underlying the metaphoric mapping underlying the passage. (The actual content of the final sentence was kept constant.) Participants read the last sentence significantly faster when it extended the existing mapping than when it drew on a new metaphoric mapping. A literal control condition established that this metaphor consistency effect was not due to lexical associations; rather, people were more fluent at reading sentences that extended the existing structural alignment than at reading sentences based on a different mapping. 
This metaphor consistency effect occurred only for novel metaphors, however. When highly conventional metaphors were used, there was no apparent cost of shifting between global metaphors. These stock metaphors were apparently processed in a localist manner, consistent with the career of metaphor claim that conventionalization results in a shift in metaphor processing toward the retrieval of prestored, domain-general meanings of base terms (Bowdle \& Gentner, 1995, 1999). This interpretation is consistent with other evidence that highly familiar idiomatic and metaphoric meanings are stored and processed at a lexical level ((Blank, 1988; Blasko \& Connine, 1993; Cacciari \& Tabossi, 1988; Gibbs, 1985, 1992, 1994; Swinney \& Cutler, 1979).

Thus, the interpretation of novel metaphors often involves the use of extended domain mappings. It is difficult to see how a categorization model of metaphor comprehension could handle such large-scale parallel structures because of its emphasis on a single, specific class-inclusion relation, rather than a connected system of relations. However, structure mapping provides a natural mechanism for explaining how extended domain mappings are processed (Gentner, 1982, 1983, 1988; Gentner \& Clement, 1988; Gentner \& Markman, 1997). According to structure-mapping theory, people construct base-to-target mappings when they read extended metaphors and extend these mappings in a structurally consistent manner across connected systems within the base and target. This predicts that metaphoric sentences will be read faster when they extend an ongoing mapping than when they require a new mapping, even when the conveyed meaning in the target is equivalent: That is, there will be a metaphor consistency effect. In contrast, categorization models predict no such consistency effect. This is because the categorization view is fundamentally localist: It assumes that each metaphor is understood by assigning the target to an abstract category derived from the literal base concept (Glucksberg \& Keysar, 1990). In this case, there is no global mapping across the entire base domain-only a series of separate category statements. Such a localist account of metaphor would predict no difference in reading time for the last lines of consistently and inconsistently mapped passages.

These findings lend support to the claim that large-scale domain metaphors are psychologically real. Further evidence comes from studies of metaphors from space to time (Gentner \& Imai, 1992; Gentner et al., 2000; McGlone \& Harding, 1998). This research capitalized on the existence of two English metaphoric space $\rightarrow$ time systems: the ego-moving metaphor, wherein the observer's context progresses along the timeline toward the future, and the time-moving metaphor, wherein time is conceived of as a river or conveyor belt on which events are moving from the future to the past. Participants were asked to understand statements about time, stated in terms of spatial metaphors: for example, "Joe's birthday is approaching" (time-moving) or "We are approaching the holidays" (ego-moving). As in the Gentner and Boronat $(1992,1999)$ studies, people's processing of the metaphors was slowed by a shift from one space-time metaphor to the other. 


\section{CONCLUSIONS}

By viewing metaphors as analogies, a number of curious aspects of metaphor are illuminated. In this article, we have described how metaphoric mappings can serve to create conventional lexical extensions of base terms and have discussed how conventionality and linguistic form interact during comprehension to determine whether a figurative statement is processed as a comparison or as a categorization, as well as whether this processing is direct or indirect. We have also shown how the analogical approach can account for metaphoric inferences, metaphoric asymmetries, and the creation of global metaphoric systems. In sum, we believe that structure-mapping theory, along with the career of metaphor hypothesis and the notion of grammatical concordance, goes a long way toward establishing a unified theoretical framework for understanding the processes involved in figurative language comprehension.

\section{ACKNOWLEDGMENTS}

This research was supported by National Science Foundation Grant SBR-95-11757 and Office of Naval Research Grant N00014-92-J-1098, awarded to Dedre Gentner. This article was prepared in part while Dedre Gentner was a Fellow at the Center for Advanced Study in the Behavioral Sciences. We are grateful for the financial support provided by the William T. Grant Foundation, Award 95167795.

We thank Rachel Giora, Albert Katz, Doug Medin, Kelly Mix, Andrew Ortony, Gregory Ward, and Phillip Wolff for their comments and suggestions.

\section{REFERENCES}

Aisenman, R. A. (1999). Structure-mapping and the simile-metaphor preference. Metaphor and Symbol, 14, 45-51.

Bassok, M., \& Holyoak, K. J. (1989). Interdomain transfer between isomorphic topics in algebra and physics. Journal of Experimental Psychology: Learning, Memory, and Cognition, 15, 153-166.

Blank, G. D. (1988). Metaphors in the lexicon. Metaphor and Symbolic Activity, 3, 21-36.

Blasko, D. G., \& Connine, C. M. (1993). Effects of familiarity and aptness on metaphor processing. Journal of Experimental Psychology: Learning, Memory and Cognition, 12, 205-308.

Boronat, C. B. (1990). Effects of base shift and frequency in extended metaphor processing. Unpublished master's thesis, University of Illinois at Urbana-Champaign.

Bowdle, B. F. (1998a). Alignment and abstraction in metaphor. In K. J. Holyoak, D. Gentner, \& B. Kokinov (Eds.), Advances in analogy research (pp. 300-307). Sofia, Bulgaria: New Bulgarian University.

Bowdle, B. F. (1998b). Conventionality, polysemy, and metaphor comprehension. Unpublished doctoral dissertation, Northwestern University, Chicago.

Bowdle, B. F., \& Gentner, D. (1995, November). The career of metaphor. Poster given at the thirty-sixth annual meeting of the Psychonomic Society, Los Angeles. 
Bowdle, B. F., \& Gentner, D. (1997). Informativity and asymmetry in comparisons. Cognitive Psychology, 34, 244-286.

Bowdle, B. F., \& Gentner, D. (1999). Metaphor comprehension: From comparison to categorization. In M. Hahn \& S. C. Stoness (Eds.), Proceedings of the twenty-first annual conference of the Cognitive Science Society (pp. 90-95). Mahwah, NJ: Lawrence Erlbaum Associates, Inc.

Bowdle, B.F., \& Gentner, D. (2001). The career of metaphor: Patterns of change in figurative language and figurative thought. Manuscript submitted for publication.

Boyd, R (1979). Metaphor and theory change: What is a "metaphor" a metaphor for? In A. Ortony (Ed.), Metaphor and thought (pp. 356-408). Cambridge, England: Cambridge University Press.

Brown, A. L., Kane, M. J., \& Echols, C. H. (1986). Young children's mental models determine analogical transfer across problems with a common goal structure. Cognitlve Development, $l$, $103-121$.

Cacciari, C., \& Tabossi, P. (1988). The comprehension of idioms. Journal of Memory and Language, $27,668-683$.

Carbonell, J. G. (1981). Invariance hierarchies in metaphor interpretation. In Proceedings of the third annual conference of the Cognitive Science Society (pp. 292-295). Hillsdale, NJ: Lawrence Erlbaum Associates, Inc.

Chiappe, D. L., \& Kennedy, J. M. (1999). Aptness predicts preference for metaphors or similes, as well as recall bias. Psychonomic Bulletin and Review, 6, 668-676.

Chiappe, D. L., \& Kennedy, J. M. (2001/this issue). Literal bases for metaphor and simile. Metaphor and Symbol, 16, 249-276.

Chomsky, N. (1961). Some methodological remarks on generative grammar. Word, 17, 219-239.

Clark, E. V. (1992). Conventionality and contrast: Pragmatic principles with lexical consequences. In A. Lehrer \& E. F. Kittay (Eds.), Frames, fields, and contrasts (pp. 171-188). Hillsdale, NJ: Lawrence Erlbaum Associates, Inc.

Clement, C. A., \& Gentner, D. (1991). Systematicity as a selection constraint in analogical mapping. Cognitive Science, 15, 89-132.

Clement, C. A., Mawby, R., \& Giles, D. E. (1994). The effects of manifest relational similarity on analog retrieval. Journal of Memory and Language, 33, 396-420.

Falkenhainer, B., Forbus, K. D., \& Gentner, D. (1989). The structure-mapping engine: Algorithm and examples. Artificial Intelligence, 41, 1-63.

Forbus, K. D., Gentner, D., \& Law, K. (1995). MAC/FAC: A model of similarity-based retrieval. Cognitive Science, 19, 141-205.

Gentner, D. (1982). Are scientific analogies metaphors? In D. S. Miall (Ed.), Metaphor: Problems and perspectives (pp. 106-132). Brighton, England: Harvester Press.

Gentmer, D. (1983). Structure-mapping: A theoretical framework for analogy. Cognitive Science, 7 , $155-170$.

Gentner, D. (1988). Metaphor as structure mapping: The relational shift. Child Development, 59, 47-59.

Gentner, D. (1989). The mechanisms of analogical learning. In S. Vosniadou \& A. Ortony (Eds.), Similarity and analogical reasoning (pp. 199-241). Cambridge, England: Cambridge University Press.

Gentner, D. (1992). Commentary on Halford's theory of cognitive development. Human Development, $35,218-221$.

Gentner, D., \& Boronat, C. B. (1992). Metaphor as mapping. Paper presented at the Workshop on Metaphor, Tel Aviv, Israel.

Gentner, D., \& Boronat, C. B. (1999). Novel metaphors are processed as generative domain-mappings. Manuscript in preparation.

Gentner, D., Bowdle, B. F., Wolff, P., \& Boronat, C. B. (2001). Metaphor is like analogy. In D. Gentmer, K. J. Holyoak, \& B. Kokinov (Eds.), The analogical mind: Perspectives from cognitive science (pp. 199-253). Cambridge, MA: MIT Press. 
Gentner, D., \& Clement, C. A. (1988). Evidence for relational selectivity in interpreting analogy and metaphor. In G. H. Bower (Ed.), The psychology of learning and motivation (pp. 307-358). New York: Academic.

Gentner, D., Falkenhainer, B., \& Skorstad, J. (1988). Viewing metaphor as analogy. In D. H. Helman (Ed), Analogical reasoning: Perspectives of artificial intelligence, computer science, and philosophy (pp. 171-178). New York: Kluwer Academic.

Gentner, D., \& Grudin, J. (1985). The evolution of mental metaphors in psychology: A 90-year retrospective. American Psychologist, 40, 181-192.

Gentner, D., \& Imai, M. (1992). Is the future always ahead? Evidence for system-mappings in understanding space-time metaphors. In Proceedings of the fourteenth annual meeting of the Cognitive Science Society (pp. 510-515). Hillsdale, NJ: Lawrence Erlbaum Associates, Inc.

Gentner, D., Imai, M., \& Boroditsky, L. (2000). As time goes by: Evidence for two systems in processing space-time metaphors. Manuscript submitted for publication.

Gentner, D., \& Markman, A. B. (1997). Structure mapping in analogy and similarity. American Psychologist, 52, 45-56.

Gentner, D., \& Wolff, P. (1997). Alignment in the processing of metaphor. Joumal of Memory and Language, 37, 331-355.

Gentner, D., \& Wolff, P. (2000). Metaphor and knowledge change. In E. Dietrich \& A. B. Markman (Eds.), Cognitive dynamics: Conceptual and representational change in humans and machines (pp. 295-342). Mahwah, NJ: Lawrence Erlbaum Associates, Inc.

Gernsbacher, M. A., Keysar, B., \& Robertson, R. R. (1995, November). The role of suppression in metaphor interpretation. Paper presented at the thirty-sixth annual meeting of the Psychonomic Society, Los Angeles.

Gerrig, R. J., \& Healy, A. F. (1983). Dual processes in metaphor understanding: Comprehension and appreciation. Journal of Experimental Psychology: Learning, Memory, and Cognition, 9, 667-675.

Gibb, H., \& Wales, R. (1990). Metaphor or simile: Psychological determinants of the differential use of each sentence form. Metaphor and Symbolic Activity, 5, 199-213.

Gibbs, R. W. (1985). On the process of understanding idioms. Joumal of Psycholinguistic Research, 14, $465-472$.

Gibbs, R. W. (1992). Categorization and metaphor understanding. Psychological Review, 99, 572-577.

Gibbs, R. W. (1994). The poetics of mind. Cambridge, England: Cambridge University Press.

Gick, M. L., \& Holyoak, K. J. (1983). Schema induction and analogical transfer. Cognitive Psychology, $15,1-38$.

Gildea, P., \& Glucksberg, S. (1983). On understanding metaphor: The role of context. Journal of Verbal Learning and Verbal Behovior, 22, 577-590.

Giora, R. (1997). Understanding figurative and literal language: The graded salience hypothesis. Cognitive Linguistics, 8, 183-206.

Glicksohn, J. (1994). Putting interaction theory to the empirical test: Some promising results. Pragmatics and Cognition, 2, 223-235.

Glucksberg, S., Gildea, P., \& Bookin, H. B. (1982). On understanding nonliteral speech: Can people ignore metaphors? Journal of Verbal Leaming and Verbal Behavior, 21, 85-98.

Glucksberg, S., \& Keysar, B. (1990). Understanding metaphorical comparisons: Beyond similarity. Psychological Review, 97, 3-18.

Glucksberg, S., McGlone, M. S., \& Manfredi, D. (1997). Property attribution in metaphor comprehension. Journal of Memory and Language, 36, 50-67.

Glucksberg, S., Newsome, M. R., \& Goldvarg, Y. (2001/this issue). Inhibition of the literal: Filtering metaphor-irrelevant information during metaphor comprehension. Metaphor and Symbol, 16. 277-293.

Gregory, M. E., \& Mergler, N. L. (1990). Metaphor comprehension: In search of literal truth, possible truth, and metaphoricity. Metaphor and Symbolic Activity, 5, 151-173. 
Grice, H. P. (1975). Logic and conversation. In P. Cole \& J. L. Morgan (Eds.), Syntax and semantics (Vol. 3, pp. 41-58). New York: Academic.

Grice, H. P. (1978). Further notes on logic and conversation. In P. Cole (Ed.), Syntax and semantics (Vol. 9, pp. 113-127). New York: Academic.

Honeck, R. P., Kibler, C. T., \& Firment, M. J. (1987). Figurative language and psychological views of categorization: Two ships in the night? In R. E. Haskell (Ed.), Cognition and symbolic structures: The psychology of metaphoric transformation (pp. 103-120). Norwood, NJ: Ablex.

Indurkhya, B. (1987). Approximate semantic transference: A computational theory of metaphor and analogy. Cognitive Science, $11,445-480$.

Inhoff, A. W., Lima, S. D., \& Carroll, P. J. (1984). Contextual effects on metaphor comprehension in reading. Memory and Cognition, 12, 558-567.

Janus, R. A., \& Bever, T. G. (1985). Processing of metaphoric language: An investigation of the three-stage model of metaphor comprehension. Journal of Psycholinguistic Research, 14, 473-487.

Johnson, M. G., \& Malgady, R. G. (1979). Some cognitive aspects of figurative language: Association and metaphor. Journal of Psycholinguistic Research, 8, 249-265.

Katz, J. J. (1964). Semi-sentences. In J. A. Fodor \& J. J. Katz (Eds.), The structure of language: Readings in a philosophy of language (pp. 400-416). Englewood Cliffs, NJ: Prentice Hall.

Katz, A. N., \& Ferretti, T. R. (2001/this issue). Moment-by-moment reading of proverbs in literal and nonliteral contexts. Metaphor and Symbol, 16, 193-221.

Kennedy, J. M. (1982). Metaphor in pictures. Perception, 11, 589-605.

Kennedy, J. M. (1990). Metaphor-Its intellectual basis. Metaphor and Symbolic Activity, 5, 115-123.

Keysar, B. (1989). On the functional equivalence of literal and metaphorical interpretations in discourse. Journal of Memory and Language, 28, 375-385.

Kintsch, W. (1974). The representation of meaning in memory. Hillsdale, NJ: Lawrence Erlbaum Associates, Inc.

Kittay, E. F., \& Lehrer, A. (1981). Semantic fields and the structure of metaphor. Studies in Language, 5 , $31-63$.

Lakoff, G. (1986). The meaning of literal. Metaphor and Symbolic Activity, 1, 291-296.

Lakoff, G. (1987). Women, fire, and dangerous things. Chicago: University of Chicago.

Lakoff, G. (1990). The invariance hypothesis: Is abstract reason based on image-schemas? Cognitive Linguistics, 1, 39-74.

Lakoff, G., \& Johnson, M. (1980). Metaphors we live by. Chicago: University of Chicago.

Lakoff, G., \& Tumer, M. (1989). More than cool reason: A field guide to poetic metaphor. Chicago: University of Chicago.

Lehrer, A. (1990). Polysemy, conventionality, and the structure of the lexicon. Cognitive Linguistics, $I$, 207-246.

Loewenstein, J., Thompson, L., \& Gentner, D. (1999). Analogical encoding facilitates knowledge transfer in negotiation. Psychonomic Bulletin and Review, 6, 586-597.

Malgady, R. G., \& Johnson, M. G. (1976). Modifiers in metaphors: Effects of constituent phrase similarity on the interpretation of figurative sentences. Journal of Psycholinguistic Research, 5, 43-52.

Marschark, M., Katz, A., \& Paivio, A. (1983). Dimensions of metaphor. Journal of Psycholinguistic Research, 12, 17-40.

Martin, J. M. (1992). Computer understanding of conventional metaphoric language. Cognitive Science, 16, 233-270.

McGlone, M. S., \& Harding, J. L. (1998). Back (or forward?) to the future: The role of perspective in temporal language comprehension. Journal of Experimental Psychology: Learning, Memory, \& Cognition, 24, 1211-1223.

Miller, G. A. (1979). Images and models, similes and metaphors. In A. Ortony (Ed.), Metaphor and thought (1st ed., pp. 202-250). Cambridge, England: Cambridge University.

Murphy, G. L. (1996). On metaphoric representation. Cognition, 60, 173-204. 
Novick, L. R., \& Holyoak, K. J. (1991). Mathematical problem solving by analogy. Journal of Experimental Psychology: Learning, Memory, and Cognition, J7, 398-415.

Nunberg, G. (1979). The non-uniqueness of semantic solutions: Polysemy. Linguistics and Philosophy, 3, 143-184.

Ortony, A. (1979). Beyond literal similarity. Psychological Review, 86, 161-180.

Ortony, A., Schallert, D., Reynolds, R., \& Antos, S. (1978). Interpreting metaphors and idioms: Some effects of context on comprehension. Journal of Verbal Learning and Verbal Behavior, 17 , $467-477$

Ramscar, M., \& Pain, H. (1996). Can a real distinction be made between cognitive theories of analogy and categorization? In Proceedings of the eighteenth annual conference of the Cognitive Science Society (pp. 346-351). Hillsdale, NJ: Lawrence Erlbaum Associates, Inc.

Ross, B. H., \& Kennedy, P. T. (1990). Generalizing from the use of earlier examples in problem solving. Journal of Experimental Psychology: Learning, Memory, and Cognition, 16, 42-55.

Searle, J. (1979). Metaphor. In A. Ortony (Ed.), Metaphor and thought (1st ed., pp. 92-123). Cambridge, England: Cambridge University Press.

Shen, Y. (1992). Metaphors and categories. Poetics Today, 13, 771-794.

Shinjo, M., \& Myers, J. L. (1987). The role of context in metaphor comprehension. Journal of Memory and Language, 26, 226-241.

Sweetser, E. (1990). From etymology to pragmatics. Cambridge, England: Cambridge University Press.

Swinney, D., \& Cutler, A. (1979). The access and processing of idiomatic expressions. Journal of Verbal Learning and Verbal Behavior, 18, 523-534.

Tourangeau, R., \& Sternberg, R. J. (1981). Aptness in metaphor. Cognitive Psychology, 13, 27-55.

Tourangeau, R., \& Stermberg, R. J. (1982). Understanding and appreciating metaphors. Cognition, II, 203-244.

Tumer, M. (1987). Death is the mother of beauty: Mind, metaphor, and criticism. Chicago: University of Chicago Press.

Tumer, N. E., \& Katz, A. N. (1997). The availability of conventional and of literal meaning during the comprehension of proverbs. Pragmatics and Cognition, 5, 199-233.

Tversky, A. (1977). Features of similarity. Psychological Review, 84, 327-352.

Verbrugge, R. R. (1980). Transformations in knowing: A realist view of metaphor. In R. P. Honeck \& R. R. Hoffman (Eds.), Cognition and figurative language (pp. 87-125). Hillsdale, NJ: Lawrence Erlbaum Associates, Inc.

Verbnugge, R. R., \& McCarrell, N. S. (1977). Metaphoric comprehension: Studies in reminding and resembling. Cognitive Psychology, 9, 494-533.

Williams, J. (1992). Processing polysemous words in context: Evidence for interrelated meanings. Journal of Psycholinguistic Research, 21, 193-218.

Wolff, P., \& Gentner, D. (2000). Evidence for role-neutral initial processing of metaphors. Journal of Experimental Psychology: Learning, Memory, and Cognition, 26, 1-13. 